\title{
Radiological Appraisal of Biodentine and Pulpotec Individually or in Combination with Photo-activated Disinfection as Pulp-capping Cements in Mature Teeth
}

\author{
Surabhi Soumya ${ }^{1}$, Gaurav Patri ${ }^{2}$, Pratik Agrawal ${ }^{3}$, Prasanti K Pradhan ${ }^{4}$, Vijeta Patri ${ }^{5}$
}

\begin{abstract}
Aim and objective: The aim of the study was to evaluate and compare radiographically, Pulpotec cement and Biodentine as direct pulp-capping agents in mature teeth, individually and in combination with photo-activated disinfection (PAD).

Material and methods: In the present study, 80 mature teeth with deep occlusal caries were selected for direct pulp-capping procedure and randomly assigned to one of the four groups [Pulpotec (I), Biodentine (II), Pulpotec + PAD (III), and Biodentine + PAD (IV)] allocating 20 teeth to each group. Direct pulp capping and cavity disinfection were performed based on the group allotted followed by permanent restoration with composite. The teeth were evaluated radiographically (densitometric analysis) at intervals of 3,6, and 12 months. The radiographic gray values obtained at follow-up periods for each group were subjected to two-way analysis of variance (ANOVA) with repeated measures.

Results: There was a significant improvement $(p<0.0001)$ in the scores of all the groups at follow-ups as compared to the baseline. There was a significant difference between group I/group II with groups III and IV ( $p=0.000)$ with group IV scoring highest at all follow-ups. However, the difference between groups I/II and groups III/IV was nonsignificant.

Conclusion: Both, Biodentine and Pulpotec can be used for direct pulp capping of mature teeth. Furthermore, PAD prior to material application significantly improved the radiographical success of Biodentine and Pulpotec, with Biodentine showing better results than Pulpotec.

Clinical significance: Biodentine and Pulpotec demonstrated comparable success as a pulp-capping agent and PAD application exhibited a synergistic effect when used in conjunction with these materials.

Keywords: Biodentine, Direct pulp capping, Mature teeth, Pulpotec.

The Journal of Contemporary Dental Practice (2021): 10.5005/jp-journals-10024-3183
\end{abstract}

\section{INTRODUCTION}

Vital pulp therapy is the first line of treatment for pulpal preservation of tooth that has been jeopardized by trauma, caries, or any restorative procedure. ${ }^{1}$ This therapy mainly comprises indirect or direct pulp capping and pulpotomy. All these procedures aim at removal of the infected tissue, preserving the integrity of healthy pulpal tissue, and consequently formation of tertiary or reparative dentin. ${ }^{2}$

Calcium hydroxide cement has been considered as the standard material in direct pulp capping for several decades. ${ }^{2}$ It acts as an effective antibacterial agent minimizing bacterial penetration and subsequent irritation of pulpal tissue. ${ }^{2}$ However, it has certain disadvantages as well, like tunnel defects in the dentinal bridge formation, notable solubility in oral fluids; lack of adhesion; disintegration with time, pulpal surface inflammation; and rarely necrosis after pulp capping. ${ }^{2,3}$ To overcome these disadvantages, mineral trioxide aggregate (MTA) and Biodentine have been introduced and are considered to be more effective in direct pulp capping (DPC) procedures. ${ }^{4}$

The MTA is a calcium silicate-based cement that induces dentin bridge formation and has demonstrated profound clinical success in comparison with $\mathrm{CH}^{4}{ }^{4}$ MTA has certain drawbacks as well like difficult handling characteristics, long setting time, high cost, and tooth discoloration potential. ${ }^{4}$ To overcome these shortcomings, Biodentine $^{\mathrm{TM}}$ (Septodont), a silicate-based bioactive dentin substitute, was introduced. ${ }^{4}$ Biodentine leads to the formation of reparative \begin{tabular}{l}
\hline${ }^{1-4}$ Department of Conservative Dentistry and Endodontics, Kalinga \\
Institute of Dental Sciences, Bhubaneswar, Odisha, India \\
${ }^{5}$ Department of Orthodontics and Dentofacial Orthopaedics, Hi Tech \\
Dental College and Hospital, Bhubaneswar, Odisha, India \\
Corresponding Author: Gaurav Patri, Department of Conservative \\
Dentistry and Endodontics, Kalinga Institute of Dental Sciences, \\
Bhubaneswar, Odisha, India, Phone: +91 9437962964, e-mail: \\
patrigaurav@gmail.com \\
How to cite this article: Soumya S, Patri G, Agrawal P, et al. Radiological \\
Appraisal of Biodentine and Pulpotec Individually or in Combination \\
with Photo-activated Disinfection as Pulp-capping Cements in Mature \\
Teeth. J Contemp Dent Pract 2021;22(9):1014-1018. \\
Source of support: Nil \\
Conflict of interest: None
\end{tabular}

dentin and when in direct contact with vital pulp tissue, it also promotes growth, proliferation, and differentiation of stem cells. ${ }^{4,5}$

Pulpotec, a radiopaque, nonresorbable paste, is a new material being used in vital pulp therapy procedures. ${ }^{6}$ Clinical trials have demonstrated success of Pulpotec cement owing to its antiseptic, hemostatic, anesthetic, antimicrobial, and anti-inflammatory actions. ${ }^{6}$ It has elicited clinical success even in cases with little residual blood in the pulp chamber. ${ }^{6}$ Though it has been used in pulpotomies, but there are no studies yet evaluating the use of this material as a direct pulp-capping agent.

(o) The Author(s). 2021 Open Access This article is distributed under the terms of the Creative Commons Attribution 4.0 International License (https://creativecommons. org/licenses/by-nc/4.0/), which permits unrestricted use, distribution, and non-commercial reproduction in any medium, provided you give appropriate credit to the original author(s) and the source, provide a link to the Creative Commons license, and indicate if changes were made. The Creative Commons Public Domain Dedication waiver (http://creativecommons.org/publicdomain/zero/1.0/) applies to the data made available in this article, unless otherwise stated. 
Literature is replete with articles stressing the importance of adequate disinfection of the cavity before pulp capping. ${ }^{1}$ This creates a conducive environment for caries arrest and remineralization. ${ }^{1}$ Photo-activated disinfection (PAD) is a such antimicrobial aid which exterminates bacteria using oxygenbased free radicals that are generated by engaging light of particular wavelength $(600-750 \mathrm{~nm})$ and a photoreactive compound (e.g., methylene blue, toluidine blue O). ${ }^{1}$ In vitro studies that have investigated the efficiency of PAD to eradicate bacteria have deduced that it could be an alternative treatment option for management of caries and cavity disinfection. ${ }^{1}$ However, there is no study till date that describes the role of PAD in combination with Pulpotec and Biodentine in direct pulp capping.

Hence, the aim of the study was to assess the radiographic outcome of Pulpotec cement and Biodentine as direct pulp-capping agents individually and in combination with PAD.

\section{Materials and Methods}

\section{Study Design}

This in vivo study (KIMS/KIIT/IEC/100/2018) was conducted on patients who reported to the Department of Conservative Dentistry and Endodontics, KIDS, Bhubaneswar, between January 2019 and January 2020 and who consented to undergo treatment and allow the use of data for academic purposes.

The patients to be included in this study were those within the age group of 18-22 years having asymptomatic deep occlusal dental caries with a diagnosis of reversible pulpitis and no radiographic signs of periapical changes or external/internal root resorption. Patients with irreversible pulpitis, chronic pulpalgia, sinus opening, internal resorption/pulpal calcification/ periradicular pathology, or uncontrollable pulpal bleeding on excavation were excluded from the study. ${ }^{1}$

\section{Clinical Procedure}

\section{Patient Selection}

Patients having deep occlusal caries on molars, following all the inclusion criteria were selected. Standardized pretreatment intraoral periapical digital radiographs (Kodak RVG 5100) were taken. A minimum total sample size of 80 teeth was chosen (20 in each of the study groups). One blinded nurse randomly allocated the patients into four groups.

$$
\begin{aligned}
& \text { Group I-Pulpotec }(n=20) \\
& \text { Group II-Biodentine }(n=20) \\
& \text { Group III-PAD + Pulpotec }(n=20) \\
& \text { Group IV-PAD + Biodentine }(n=20)
\end{aligned}
$$

\section{Procedure}

Local anesthesia (2\% lidocaine hydrochloride with epinephrine 1:80,000; Septodont) was administered by nerve block. Rubber dam isolation was done (Hygenic; Coltene/Whaledent AG) before caries removal. Loupes were used for magnification during the operative procedure. A caries detector dye (Kuraray Noritake Dental Inc.) was used prior to excavation. Complete removal of caries from the lateral walls of the cavity was carried out with a sterile round bur (MANI Diamond Burs) that was mounted to a high-speed handpiece. The carious portion on the floor of the cavity was then manually removed with a sterile spoon excavator (Dentsply). During instrumentation, when pin-point exposure occurred $(<0.5 \mathrm{~mm})$, hemostasis was accomplished by exerting pressure, for not more than 10 minutes over the exposure with cotton pellets soaked in sterile saline solution. If bleeding persisted, the patient was excluded from the study. Following excavation, pulp capping was performed according to the group in which the patient was allocated. The materials were manipulated based on the manufacturers' instructions.

\section{Experimental Groups}

Group I: Pulpotec cement (Product Dentaires SA) was manipulated and applied over the exposed pulp with a plastic filling instrument. The tooth was then temporized using Cavit G (EM ESPE). The patient was recalled after 24 hours and the tooth was permanently restored with composite.

Group II: Biodentine (Septodont) was manipulated and applied over the exposed pulp with a plastic filling instrument. Once set, composite restoration was done.

Group III: $0.01 \mathrm{mg} / \mathrm{mL}$ of Tolonium Chloride dye (Denfotex Light Systems Ltd., Fife, UK) was applied to the cavity walls adjacent to the exposure site with a microbrush for 60 seconds following which laser irradiation (PAD) was done with a diode laser ( $635 \mathrm{~nm}$ wavelength for 60 seconds) aimed $2 \mathrm{~mm}$ from the carious dentin. The cavity was sluiced with sterile saline and dried using cotton pellets.

Pulpotec cement was placed on the exposed pulp. The tooth was then temporized and the patient was recalled after 24 hours for permanent restoration with composite.

Group IV: Similar to group III, PAD was performed following which Biodentine was placed on the exposed pulp, once set, the cavity was permanently restored with composite.

The patients were recalled at 3-, 6-, and 12-month intervals for radiographic (densitometric) analysis.

Kodak RVG (Trophy Imaging software 6.12.10.0) was used to measure, radiographically, the relative density of the dentin bridge formed.

The "Intraoral" option in the main menu bar was used. The "Tools window" was selected and "Densitometric analysis" option was clicked. Two repeatable points (i.e., A and B) were located in the postoperative and subsequent follow-up radiographs. " $A$ " denoted a mark $0.5 \mathrm{~mm}$ underneath the deepest section of the restored cavity and " $\mathrm{B}$ " a mark perpendicular to A on the pulp chamber roof.

The average gray value along the line joining the two points was noted and correlated with the data obtained on subsequent follow-up. Statistical tests were performed using the SPSS V20 software (SPSS Inc.).

\section{ResUlts}

The mean scores of individual groups have been mentioned in Table 1. Based on the criteria laid down to evaluate treatment success, all groups showed improvement in the scores over the time period. The radiographic values obtained for each group at all the follow-up periods were analyzed using the two-way analysis of variance (ANOVA) with repeated measures. There was a significant improvement $(p<0.0001)$ in the scores of all the groups at follow-ups as compared to the baseline. The highest score was noted for group IV at all follow-ups (Table 1).

\section{At 3 Months}

Group I showed statistically significant difference when compared to group III and IV ( $p=0.001 / 0.000)$. Group II showed statistically significant difference when compared to group IV ( $p=0.001)$. On 
Biodentine and Pulpotec with PAD as Pulp-capping Cements

Table 1: Mean scores of the groups compared at various intervals

\begin{tabular}{|c|c|c|c|c|c|c|c|c|}
\hline \multicolumn{9}{|c|}{ Descriptive statistics } \\
\hline Groups & Time duration & $N$ & Mean & Std. deviation & Minimum & Maximum & Chi-squared & $p$ value \\
\hline \multirow[t]{4}{*}{$\mathrm{I}$} & Baseline & 20 & 174.75 & 2.511 & 170 & 179 & 60.000 & $<0.0001^{*}$ \\
\hline & 3 months & 20 & 177.75 & 2.314 & 173 & 182 & & \\
\hline & 6 months & 20 & 182.65 & 2.601 & 176 & 187 & & \\
\hline & 12 months & 20 & 189.10 & 2.426 & 183 & 193 & & \\
\hline \multirow[t]{4}{*}{ ॥ } & Baseline & 20 & 175.50 & 2.606 & 171 & 179 & 59.714 & $<0.0001^{*}$ \\
\hline & 3 months & 20 & 178.85 & 2.033 & 175 & 182 & & \\
\hline & 6 months & 20 & 183.10 & 2.269 & 179 & 186 & & \\
\hline & 12 months & 20 & 189.85 & 1.899 & 187 & 193 & & \\
\hline \multirow[t]{4}{*}{ III } & Baseline & 20 & 177.35 & 2.601 & 172 & 181 & 60.000 & $<0.0001^{*}$ \\
\hline & 3 months & 20 & 180.60 & 2.393 & 176 & 184 & & \\
\hline & 6 months & 20 & 186.15 & 2.277 & 182 & 189 & & \\
\hline & 12 months & 20 & 194.00 & 2.248 & 190 & 197 & & \\
\hline \multirow[t]{4}{*}{ IV } & Baseline & 20 & 177.80 & 2.567 & 171 & 181 & 60.000 & $<0.0001^{*}$ \\
\hline & 3 months & 20 & 181.50 & 2.212 & 176 & 185 & & \\
\hline & 6 months & 20 & 187.05 & 2.012 & 183 & 191 & & \\
\hline & 12 months & 20 & 194.65 & 1.843 & 191 & 198 & & \\
\hline
\end{tabular}

*Statistically significant

comparison between group III/IV and group I/II, the results were not significant (Table 2).

\section{At 6 Months}

There was a significant increase $(p<0.0001)$ in gray level for all the four groups. There was a significant difference between group I/ group II with groups III and IV ( $p=0.000)$. However, the difference between groups I and II and groups III and IV was nonsignificant ( $p=0.926,0.605$, respectively) (Table 2 ).

\section{At 12 Months}

There was a significant increase $(p<0.0001)$ in gray values for all the experimental groups. There was a significant difference between group I/group II with groups III and IV ( $p=0.00)$. However, the difference between groups I and II and groups III and IV was nonsignificant ( $p=0.679$ and 0.767 , respectively) (Table 2).

\section{Discussion}

Pulpal preservation is instrumental for its physiologic function maintenance, for unhindered root maturation in immature tooth and to facilitate odontoblasts for dentinal bridge formation at the pulp medicament interface. ${ }^{7}$

Quantitative radiographic evaluation is a beneficial attribute of digital diagnostic imaging. The radiographic density, expressed in numeric values based on the grey levels, is a measure of degree of image darkening. This value is obtained using the "computerassisted densitometric image analysis" (CADIA) software which distinguishes subtle changes in the hard tissue mineralization. ${ }^{1,8}$

Kodak RVG Dental Imaging software, used in this study, incorporates a very similar tool that aids in quantifying the density at a definite point within the radiogram. Studies conducted by Di Alberti et al., ${ }^{9}$ Radionov et al., ${ }^{10}$ and Sharma et al. ${ }^{1}$ demonstrated that RVG densitometry showed reliable values of bone density. In this study, it was observed that in every group during the follow-up periods, there was an increase in the radiographic gray values. This may be due to remineralization of the dentin resulting from the biological response of the pulp to the bioactive cements and the microbiocidal activity of PAD.

In this study, at all time intervals, both Biodentine and Pulpotec cements as a direct pulp-capping agent for reparative dentin formation showed comparable results, with Biodentine showing better although not statistically significant results. The results of Biodentine are in accordance with previous literature available on Biodentine that shows its ability to form reparative dentin. ${ }^{4,7,11}$ Laurent et al. ${ }^{12}$ and Nowicka et al. ${ }^{13}$ concluded that when Biodentine was applied directly onto pulp, it induces a reparative dentine formation due to modulation of pulp cell TGF-beta secretion and early odontoblastic differentiation with initiation of mineralization. Among all the cements used for direct pulp capping, Biodentine stands out because of its biocompatibility, faster setting, high compressive strength, antimicrobial property, and ease of manipulation. ${ }^{7,11,14}$

The results of Pulpotec cement in this study cannot be collated as there is no literature in this regard. Pulpotec, a new material, is being widely used in pedodontics for vital pulp therapy. It shows a strong antibacterial effect against various microorganisms like Enterococcus faecalis and Klebsiella spp. Pulpotec causes cicatrization of exposed pulp while maintaining the underlying integrity of pulp. It also possesses hemostatic and anti-inflammatory properties with sustained efficacy even in contact with residual blood. It induces reparative dentin formation from injured odontoblasts and cells from sub-odontoblastic Hoehl's layer. The above-described properties of Pulpotec cement rationalize its use as a direct pulp-capping agent. ${ }^{15-17}$

On intergroup comparison, group III and group IV showed significantly better results as compared to groups I and II at all the time frames. This may be due to the use of PAD for cavity disinfection prior to restoration that provides a favorable caries free environment for dentin remineralization. ${ }^{1,18}$ Williams et al. ${ }^{19}$ evaluated the effectiveness of PAD against Streptococcus mutans in carious dentin and collagen matrix and concluded that PAD could obtain $99 \%$ bactericidal activity. Streptococcus sobrinus, 
Table 2: Intergroup comparisons between the groups at various time intervals

\begin{tabular}{|c|c|c|c|c|c|c|c|}
\hline \multicolumn{8}{|c|}{ Multiple comparisons } \\
\hline \multicolumn{8}{|c|}{ Tukey's honestly significant difference (HSD) test } \\
\hline \multirow[b]{2}{*}{ Dependent variables } & \multirow[b]{2}{*}{ (I) Group } & \multirow[b]{2}{*}{ (J) Group } & \multirow[b]{2}{*}{ Mean difference $(I-J)$} & \multirow[b]{2}{*}{ Std. error } & \multirow[b]{2}{*}{ Sig. } & \multicolumn{2}{|c|}{ 95\% Confidence interval } \\
\hline & & & & & & Lower bound & Upper bound \\
\hline \multirow[t]{12}{*}{ Baseline } & 1 & II & -0.750 & 0.813 & 0.793 & -2.89 & 1.39 \\
\hline & & III & $-2.600^{*}$ & 0.813 & 0.011 & -4.74 & -0.46 \\
\hline & & IV & $-3.050^{*}$ & 0.813 & 0.002 & -5.19 & -0.91 \\
\hline & $\|$ & I & 0.750 & 0.813 & 0.793 & -1.39 & 2.89 \\
\hline & & III & -1.850 & 0.813 & 0.113 & -3.99 & 0.29 \\
\hline & & IV & $-2.300^{*}$ & 0.813 & 0.030 & -4.44 & -0.16 \\
\hline & III & I & $2.600^{*}$ & 0.813 & 0.011 & 0.46 & 4.74 \\
\hline & & ॥ & 1.850 & 0.813 & 0.113 & -0.29 & 3.99 \\
\hline & & IV & -0.450 & 0.813 & 0.945 & -2.59 & 1.69 \\
\hline & IV & I & $3.050^{*}$ & 0.813 & 0.002 & 0.91 & 5.19 \\
\hline & & $\|$ & $2.300^{*}$ & 0.813 & 0.030 & 0.16 & 4.44 \\
\hline & & III & 0.450 & 0.813 & 0.945 & -1.69 & 2.59 \\
\hline \multirow[t]{12}{*}{3 months } & I & $\|$ & -1.100 & 0.709 & 0.412 & -2.96 & 0.76 \\
\hline & & III & $-2.850^{*}$ & 0.709 & 0.001 & -4.71 & -0.99 \\
\hline & & IV & $-3.750^{*}$ & 0.709 & 0.000 & -5.61 & -1.89 \\
\hline & $\|$ & I & 1.100 & 0.709 & 0.412 & -0.76 & 2.96 \\
\hline & & III & -1.750 & 0.709 & 0.073 & -3.61 & 0.11 \\
\hline & & IV & $-2.650^{*}$ & 0.709 & 0.002 & -4.51 & -0.79 \\
\hline & III & I & $2.850^{*}$ & 0.709 & 0.001 & 0.99 & 4.71 \\
\hline & & II & 1.750 & 0.709 & 0.073 & -0.11 & 3.61 \\
\hline & & IV & -0.900 & 0.709 & 0.585 & -2.76 & 0.96 \\
\hline & IV & I & $3.750^{*}$ & 0.709 & 0.000 & 1.89 & 5.61 \\
\hline & & $\|$ & $2.650^{*}$ & 0.709 & 0.002 & 0.79 & 4.51 \\
\hline & & III & 0.900 & 0.709 & 0.585 & -0.96 & 2.76 \\
\hline \multirow[t]{12}{*}{6 months } & 1 & $\|$ & -0.450 & 0.727 & 0.926 & -2.36 & 1.46 \\
\hline & & III & $-3.500^{*}$ & 0.727 & 0.000 & -5.41 & -1.59 \\
\hline & & IV & $-4.400^{*}$ & 0.727 & 0.000 & -6.31 & -2.49 \\
\hline & ॥ & I & 0.450 & 0.727 & 0.926 & -1.46 & 2.36 \\
\hline & & III & $-3.050^{*}$ & 0.727 & 0.000 & -4.96 & -1.14 \\
\hline & & IV & $-3.950^{*}$ & 0.727 & 0.000 & -5.86 & -2.04 \\
\hline & III & I & $3.500^{*}$ & 0.727 & 0.000 & 1.59 & 5.41 \\
\hline & & $\|$ & $3.050^{*}$ & 0.727 & 0.000 & 1.14 & 4.96 \\
\hline & & IV & -0.900 & 0.727 & 0.605 & -2.81 & 1.01 \\
\hline & IV & I & $4.400^{*}$ & 0.727 & 0.000 & 2.49 & 6.31 \\
\hline & & $\|$ & $3.950^{*}$ & 0.727 & 0.000 & 2.04 & 5.86 \\
\hline & & III & 0.900 & 0.727 & 0.605 & -1.01 & 2.81 \\
\hline \multirow[t]{12}{*}{12 months } & 1 & $\|$ & -0.750 & 0.670 & 0.679 & -2.51 & 1.01 \\
\hline & & III & $-4.900^{*}$ & 0.670 & 0.000 & -6.66 & -3.14 \\
\hline & & IV & $-5.550^{*}$ & 0.670 & 0.000 & -7.31 & -3.79 \\
\hline & ॥ & I & 0.750 & 0.670 & 0.679 & -1.01 & 2.51 \\
\hline & & III & $-4.150^{*}$ & 0.670 & 0.000 & -5.91 & -2.39 \\
\hline & & IV & $-4.800^{*}$ & 0.670 & 0.000 & -6.56 & -3.04 \\
\hline & III & I & $4.900^{*}$ & 0.670 & 0.000 & 3.14 & 6.66 \\
\hline & & $\|$ & $4.150^{*}$ & 0.670 & 0.000 & 2.39 & 5.91 \\
\hline & & IV & -0.650 & 0.670 & 0.767 & -2.41 & 1.11 \\
\hline & IV & I & $5.550^{*}$ & 0.670 & 0.000 & 3.79 & 7.31 \\
\hline & & II & $4.800^{*}$ & 0.670 & 0.000 & 3.04 & 6.56 \\
\hline & & III & 0.650 & 0.670 & 0.767 & -1.11 & 2.41 \\
\hline
\end{tabular}

"The mean difference is significant at the 0.05 level. The bold values suggest statistical significant result 
Lactobacillus casei, and Actinomyces viscosus are microorganisms against which PAD is equally effective. ${ }^{1}$

$P A D$, the most recent antimicrobial strategy, involves the use of a nontoxic photosensitizer (PS) compound or dye and a nonharmful visible light source for cavity disinfection. Low-power laser in itself is not lethal to bacteria, but it causes photochemical activation of oxygen-releasing dyes. Singlet oxygen released from dyes causes membrane and DNA damage to microorganisms. ${ }^{1,20}$

In this study, toluidine blue dye $(0.01 \mathrm{mg} / \mathrm{mL}$ tolonium chloride, Denfotex Light Systems Ltd., UK) has been used which is a photo-sensitizer compound belonging to phenothiazinium class. Its penetration into both gram-positive and gram-negative microorganisms is due to its amphiphilic nature. The dye concentration of $0.01 \mathrm{mg} / \mathrm{mL}$ tolonium chloride has been used as for values greater than this "self-aggregates" (dimeric form) are formed that modifies its absorption spectrum. A laser of $635 \mathrm{~nm}$ wavelength coincident with the absorption spectrum of the dye was used. An energy dose of $6 \mathrm{~J}$ ( 60 seconds $\times 100 \mathrm{~mW}, 1 \mathrm{~mW}=0.001$ $\mathrm{J} /$ seconds) was used for the study which has been shown to exert adequate antibacterial activity and is safe for pulp vitality. 1,21,22

The limitations in this study were a short follow-up period and the clinical parameters were not assessed or collaborated with the radiographic findings. Further studies addressing these lacunae need to be conducted.

\section{ConCLUSION}

Based on the limitations of this study, it can thus be concluded that:

Both Biodentine and Pulpotec cement showed comparable results and can be used as pulp-capping agents. The conjunction of PAD with bioactive cements significantly improved the treatment outcome, with Biodentine showing the best treatment outcome.

\section{Acknowledgments}

The authors wish to express gratitude to the patients for participating in the study.

\section{Research Approval}

Institute research ethics committee approval (KIMS/KIIT/ IEC/100/2018) was obtained prior to the study.

\section{References}

1. Sharma S, Logani A, Shah N. Comparative efficacy of photo-activated disinfection and calcium hydroxide for disinfection of remaining carious dentin in deep cavities: a clinical study. Restor Dent Endod 2014;39(3):195-200. DOI: 10.5395/rde.2014.39.3.195.

2. Li Z, Cao L, Fan M, et al. Direct pulp capping with calcium hydroxide or mineral trioxide aggregate: a meta-analysis. J Endod 2015;41(9): 1412-1417. DOI: 10.1016/j.joen.2015.04.012.

3. Elchaghaby MA, Moheb DM, El Shahawy OI, et al. Clinical and radiographic evaluation of indirect pulp treatment of young permanent molars using photo-activated oral disinfection versus calcium hydroxide: a randomized controlled pilot trial. BDJ Open 2020;6(1):1-7. DOI: 10.1038/s41405-020-0030-z.

4. Katge FA, Patil DP. Comparative analysis of 2 calcium silicate-based cements (Biodentine and Mineral Trioxide Aggregate) as direct pulpcapping agent in young permanent molars: a split mouth study. J Endod 2017;43(4):507-513. DOI: 10.1016/j.joen.2016.11.026.
5. Hargreaves KM, Goodis HE, Tay FR, editors. Seltzer and Bender's dental pulp. Quintessence Pub.; 2012.

6. Sunitha B, Puppala R, Kethineni B, et al. Clinical and radiographic evaluation of four different pulpotomy agents in primary molars: a longitudinal study. Int J Clin Pediatr Dent 2017;10(3):240. DOI: 10.5005/ jp-journals-10005-1443.

7. Brizuela C, Ormeño A, Cabrera C, et al. Direct pulp capping with calcium hydroxide, mineral trioxide aggregate, and biodentine in permanent young teeth with caries: a randomized clinical trial. J Endod 2017;43(11):1776-1780. DOI: 10.1016/j.joen.2017.06.031.

8. Park YS, Bae KH, Chang J, et al. Theory of X-ray microcomputed tomography in dental research: application for the caries research. J Kor Acad Conserv Dent 2011;36(2):98-107. DOI: 10.5395/ JKACD.2011.36.2.98.

9. Di Alberti L, Donnini F, Di Alberti C, et al. A comparative study of bone densitometry during osseointegration: piezoelectric surgery versus rotary protocols. Quintessence Int 2010;41(8):639-644. PMID: 20657852.

10. Radionov D, Lulić-Dukić $O$, Gasparac I. Osteointegration of a replanted tooth followed by RVG densitometry. Coll Antropol 1998;22:161-166. PMID: 9951158.

11. Tziafa C, Koliniotou-Koumpia E, Papadimitriou S, et al. Dentinogenic responses after direct pulp capping of miniature swine teeth with Biodentine. J Endod 2014;40(12):1967-1971. DOI: 10.1016/ j.joen.2014.07.021.

12. Laurent $\mathrm{P}, \mathrm{Camps} J$, About I. Biodentine $\mathrm{e}^{\mathrm{TM}}$ induces TGF- $\beta 1$ release from human pulp cells and early dental pulp mineralization. Int Endod J 2012;45(5):439-448. DOI: 10.1111/j.1365-2591.2011.01995.x.

13. Nowicka A, Lipski M, Parafiniuk M, et al. Response of human dental pulp capped with biodentine and mineral trioxide aggregate. J Endod 2013;39(6):743-747. DOI: 10.1016/j.joen.2013.01.005.

14. Kim JR, Nosrat A, Fouad AF. Interfacial characteristics of Biodentine and MTA with dentine in simulated body fluid. J Dentist 2015;43(2): 241-247. DOI: 10.1016/j.jdent.2014.11.004.

15. Kakarla P, Avula JS, Mellela GM, et al. Dental pulp response to collagen and pulpotec cement as pulpotomy agents in primary dentition: a histological study. J Conserv Dent 2013;16(5):434. DOI: 10.4103/09720707.117525.

16. Al-Dahan ZA, Zwain AM, Al-Assadi AH. Clinical and radiographical evaluation of pulpotomy in primary molars treated with Pulpotec (PD), Formocresol and Mineral Trioxide Aggregate (MTA). Dentistry 2013;25(4):164-170. Available from: https://jbcd.uobaghdad.edu.iq/ index.php/jbcd/article/view/188.

17. Mythraiye R, Rao VV, Babu MM, et al. Evaluation of the clinical and radiological outcomes of pulpotomized primary molars treated with three different materials: Mineral Trioxide Aggregate, Biodentine, and Pulpotec. An in-vivo study. Cureus 2019;11(6). DOI: 10.7759/ cureus.4803.

18. Giusti JS, Santos-Pinto L, Pizzolito AC, et al. Antimicrobial photodynamic action on dentin using a light-emitting diode light source. Photomed Laser Surg 2008;26(4):281-287. DOI: 10.1089/ pho.2007.2149.

19. Williams JA, Pearson GJ, Colles MJ, et al. The photo-activated antibacterial action of toluidine blue $\mathrm{O}$ in a collagen matrix and in carious dentine. Caries Res 2004;38(6):530-536. DOI: 10.1159/000080582.

20. Mohan $D$, Maruthingal $S$, Indira R, et al. Photoactivated disinfection (PAD) of dental root canal system - an ex-vivo study. Saudi J Biol Sci 2016;23(1):122-127. DOI: 10.1016/j.sjbs.2015.01.013.

21. Nagata JY, Hioka N, Kimura E, et al. Antibacterial photodynamic therapy for dental caries: evaluation of the photosensitizers used and light source properties. Photodiagnosis Photodyn Ther 2012;9(2): 122-131. DOI: 10.1016/j.pdpdt.2011.11.006.

22. Nammour S, Zeinoun T, Bogaerts I, et al. Evaluation of dental pulp temperature rise during photo-activated decontamination (PAD) of caries: an in vitro study. Lasers Med Sci 2010;25(5):651-654. DOI: 10.1007/s10103-009-0683-2. 